\title{
INTERACCIÓN DE HONGOS MICORRÍZICOS ARBUSCULARES Y UNA CEPA FOSFATO SOLUBILIZADORA EN CANAVALIA ENSIFORMIS (FABACEAE)
}

\section{INTERACTION WITH ARBUSCULAR MYCORRHIZAL AND PHOSPHATE SOLUBILIZER FUNGI IN CANAVALIA ENSIFORMIS (FABACEAE)}

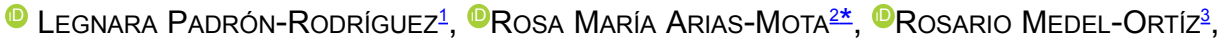 \\ OYAdeneyro De la CRUZ-Elizondo4
}

\author{
${ }^{1}$ Facultad de Ciencias Agrícolas. Universidad Veracruzana. Campus Xalapa, Ver. México \\ ${ }^{2}$ Instituto Tecnológico Superior de Xalapa. Ver. México. \\ ${ }^{3}$ Centro de Investigación en Micología Aplicada. Xalapa, Ver. México \\ ${ }^{4}$ Facultad de Biología. Universidad Veracruzana. Campus Xalapa, Ver. México.
}

*Autor de correspondencia: rosa.arias@itsx.edu.mx

\section{Resumen}

Antecedentes: Canavalia ensiformis es una leguminosa forrajera de origen tropical ampliamente utilizada como abono verde. El uso de hongos micorrízicos y solubilizadores de fósforo es una alternativa agronómicamente viable y sustentable aplicada en cultivos de importancia económica.

Hipótesis: La interacción de hongos micorrízicos arbusculares y solubilizadores de fósforo favorecerá la colonización micorrízica, la disponibilidad de fósforo y el crecimiento de las plantas de C. ensiformis.

Métodos: Este estudio se realizó de marzo 2018-agosto 2019 en un invernadero con la planta cobertera C. ensiformis, un inóculo micorrízico y Penicillium brevicompactum, todas las posibles combinaciones con tres repeticiones en tres ciclos. Se evalúo la altura, número de hojas y nódulos por planta. Se tomaron muestras de raíces y suelo para determinar colonización micorrízica y P soluble. Los datos fueron analizados mediante ANOVA Factorial y test de Tukey $(\alpha=0.05)$.

Resultados: En los tres ciclos, la micorrización fue significativamente mayor en las plantas inoculadas con la interacción HMA+HSF (Tukey < 0.05). Esta interacción favoreció un incremento de $3.07 \mathrm{mg} / \mathrm{Kg}$ de P soluble en el suelo. Los tratamientos de HSF y HMA+HSF incrementaron significativamente las variables de crecimiento de las plantas (altura y número de hojas) $(p<0.05)$. El número de nódulos osciló entre 46-76 y se detectó un efecto significativo del factor HMA $(p<0.05)$ y del HSF $(p<0.05)$.

Conclusiones: La aplicación de las interacciones de HMA y HSF aumentó la colonización micorrízica, la disponibilidad de fósforo en el suelo y el crecimiento de las plantas de C. ensiformis.

Palabras clave: Biofertilizantes, fósforo, microorganismos, nutrición.

\begin{abstract}
Background: Canavalia ensiformis is a forage legume of tropical origin widely used as green manure. The use of mycorrhizal fungi and phosphorus solubilizers is an agronomically viable and sustainable alternative applied in economic importance crops.

Hypothesis: The interaction of arbuscular mycorrhizal fungi and phosphorus solubilizers will favor mycorrhizal colonization, phosphorus availability and the growth of $C$. ensiformis plants.

Methods: It was carried out 2018 march to 2019 august in the greenhouse with the $C$. ensiformis cover plant, a mycorrhizal inoculum and Penicillium brevicompactum, all possible combinations with three repetitions for three cycles. Height, number of leaves and nodules per plant were measured. Root and soil samples were taken to determine mycorrhizal colonization and soluble P. Data were analyzed using Factorial ANOVA and Tukey test $(\alpha=0.05)$.

Results: In all three cycles, mycorrhization was significantly higher in the plants inoculated with AMF + PSF interaction (Tukey $<0.05$ ). This interaction favored an increase of $3.07 \mathrm{mg} / \mathrm{Kg}$ of soluble P in the soil. PSF and AMF + PSF treatments increased plant growth variables (height and number of leaves) $(p<0.05)$. The number of nodules ranged from $46-76$ and a significant effect of the AMF factor $(p<0.05)$ and PSF $(p<0.05)$ was detected.

Conclusions: The application of AMF and PSF interactions increased mycorrhizal colonization, the availability of phosphorus in the soil and the growth of C. ensiformis plants.
\end{abstract}

Keywords: Biofertilizers, microorganisms, nutrition, phosphorus. 
Canavalia ensiformis (L.) DC es una leguminosa anual de origen tropical (Beyra-Matos et al. 2004), utilizada como productora de forraje principalmente por su alta eficiencia fotosintética y consecuente acumulación de biomasa en forma de forraje verde disponible (FVD), con alto valor proteico (Peters et al. 2003). Su utilización como cultivo de cobertura está tomando mayor importancia en una variedad de sistemas agrícolas, donde se aprovecha como abono verde durante temporadas de sequía. Los abonos verdes representan una alternativa de incremento y conservación de la fertilidad de los suelos (García et al. 2002). El valor del abonado verde consiste fundamentalmente en el aporte de nitrógeno de las leguminosas, que en simbiosis con bacterias del género Rhizobium y a través de la fijación biológica del nitrógeno $\left(500 \mathrm{Kg} \mathrm{N} \mathrm{ha}{ }^{-1}\right)$ y posterior mineralización del elemento en el suelo reduce los requerimientos de fertilizantes nitrogenados de los cultivos (Oberson et al. 2013).

En el suelo existe una diversidad de interacciones reguladas por la presencia de microorganismos funcionales, como fijadores de nitrógeno, solubilizadores de fosfatos, promotores del crecimiento vegetal, biocontroladores y especies patogénicas, que compiten por espacio y por nutrientes (Reyes-Jaramillo 2011). Estas interrelaciones inciden en la interacción suelo-planta-microorganismosambiente y repercuten de forma directa, en el crecimiento y en el desarrollo de las especies vegetales.

Los hongos micorrízicos arbusculares (HMA) y hongos solubilizadores de fósforo (HSF) son microorganismos promotores del crecimiento vegetal conocidos como PGPM (Plant Growth-Promoting Microorganism), que dependen de factores bióticos y abióticos para expresar sus potenciales efectos benéficos; en la interacción de estos microorganismos, se pueden presentar efectos sinérgicos, que potencialicen los beneficios, efectos antagónicos o efectos neutros en el crecimiento y en el desarrollo de las plantas (Cano 2011). Los HMA facilitan la absorción del fósforo presente en el suelo, brindan protección frente al estrés abiótico, contra patógenos y mejoran la estructura del suelo (Li et al. 2006, Miransari et al. 2008). Los organismos solubilizadores de fósforo por otro lado, tienen la habilidad de transformar el $\mathrm{P}$ insoluble a soluble, al romper los enlaces que forma este elemento con iones metálicos (Fe, Ca y Al) (Restrepo-Correa et al. 2017).

Diversos estudios han evidenciado los efectos positivos de las co-inoculaciones de microorganismos solubilizadores de P y HMA en tomate (Velázquez et al. 2005), frijol (Zaidi \& Khan 2006), trébol (Souchie et al. 2006), bambú (Babu \& Reddy 2011), anacardo (Rodrigues-Cabral et al. 2012), chile (Castillo et al. 2013), aguacate (Serna 2013), frijol caupí (Ramírez-Gil et al. 2013), garbanzo (Saxena et al. 2015), lechuga (Velázquez et al. 2017); Coffea arabica (Perea-Rojas et al. 2019); jitomate (Arias et al. 2019). Sin embargo, otros estudios han reportado efectos negativos (McAllister et al. 1995, Gryndler et al. 2002) o neutros (Edwards et al. 2010). A la fecha, no existen estudios que abordan el efecto de las co-inoculaciones de HMA y HSF en leguminosas. El presente estudio tiene por objetivo probar el efecto de las co-inoculaciones de HMA y HSF en plantas de C. ensiformis.

\section{Materiales y métodos}

El inóculo de HMA (Rizofermic), fue provisto por el Laboratorio de Organismos Benéficos de la Facultad de Ciencias Agrícolas de la Universidad Veracruzana. Este inóculo es un consorcio formado por 12 especies de HMA: Acaulospora morrowiae, A. spinosa, A. scrobiculata, Gigaspora rosea, G. decipiens, Scutellospora pellucida, Glomus macrocarpum, G. aggregatum, Funneliformis mosseae, F. geosporus, Rhizophagus intraradices, Claroideoglomus etunicatum.

Se empleó una cepa de hongo solubilizador de fosfato Penicillium brevicompactum, que se obtuvo del Laboratorio de Micromicetos del INECOL A. C. Este hongo fue aislado de suelo de cafetales del estado de Veracruz y fue seleccionada por su alta capacidad fosfato solubilizadora en estudios previos (Perea-Rojas 2013). La cepa del HSF se reactivó en medio de cultivo sólido Papa Dextrosa Agar (PDA), en placas de Petri de $90 \times 110 \mathrm{~mm}$ y se incubó a $25^{\circ} \mathrm{C}$ por 15 días en la oscuridad. Una vez activada se pasó a medio de cultivo Extracto de Malta Agar (EMA) para buscar una mayor esporulación. Transcurridos 15 días se obtuvo una suspensión de esporas que se llevó posteriormente a conteo en cámara de Neubauer bajo un microscopio compuesto (Nikon ECLIPSE 80i) para ajustarla a una concentración de $1 \times 10^{8} \mathrm{UFC} / \mathrm{mL}$, tal como lo propone (Souchie et al. 2010).

En cada ciclo se germinaron semillas de C. ensiformis en charolas plásticas con arena estéril durante 7 días. Las semillas de C. ensiformis, fueron proporcionadas por la empresa Leguminutre. Una vez germinadas las plántulas se trasplantaron a macetas de $1,5 \mathrm{Kg}$ con suelo estéril y tepezil $(1: 1 \mathrm{v} / \mathrm{v})$. Al momento del trasplante se inocularon los HMA (10 gr/planta) directamente a la raíz. Luego de 10 días se inoculó el HSF a las raíces de las plantas a una concentración de $1 \times 10^{8} \mathrm{UFC} / \mathrm{mL}(3 \mathrm{~mL})$.

Posterior a la inoculación, las plantas permanecieron 30 días en el invernadero con riego manual cada tercer día, trascurrido el tiempo se cosecharon, pesaron y tomaron muestras de raíces. Se reincorporó la biomasa a las macetas y se dejaron 45 días manteniendo la humedad del sustrato para favorecer el proceso de mineralización. Esta metodología se repitió durante tres ciclos consecutivos; cada ciclo duró tres meses e incluyó la siembra, cosecha y el tiempo de descomposición de la biomasa; en total el ensayo duro 9 meses. 
Evaluación de la colonización micorrízica. Para evaluar el porcentaje de micorrización, las raíces se tiñeron siguiendo la técnica de clareo y tinción de Phillips \& Hayman (1970) y se estimó el porcentaje de colonización micorrízica, de acuerdo con el método de Giovannetti \& Mosse (1980).

Determinación del fósforo soluble en el suelo. Una vez secas y tamizadas las muestras de suelo, se tomaron $2.5 \mathrm{~g} \mathrm{y}$ se siguió la técnica de cuantificación de fósforo soluble de Bray \& Kurtz (1945). Se midieron las reacciones colorimétricas en un espectrofotómetro a una longitud de onda de $882 \mathrm{~nm}$ (Thermo Scientific GENESYS 10S UVUVS).

Medición de variables de crecimiento (altura, número de hojas y número de nódulos). La altura de las plantas se midió con una regla métrica y se expresó en $\mathrm{cm}$. Se realizó un conteo del número de hojas y número de nódulos por planta en el momento de la cosecha.

Diseño experimental y análisis estadístico. El ensayo se realizó bajo un diseño completamente aleatorizado con arreglo factorial $2 \times 4$; una planta cobertera: $C$. ensiformis; dos factores (tiempo; interacción entre HMA y HSF), y 4 tratamientos: 1) HMA; 2) HSF; 3) HMA + HSF; y 4) Control (sin hongos). Se realizaron tres repeticiones de cada tratamiento; el ensayo tuvo un tiempo de duración de 276 días. Dado que los datos cumplían con el supuesto de normalidad (Shapiro Wilk) y homogeneidad de varianza (Bartlett)se sometieron a un ANOVA Factorial $(\alpha=0.05$; intervalo de confianza $95 \%$ ) y se les realizó una prueba post hoc de Tukey $(\alpha=0.05)$. Los análisis estadísticos se realizaron con el programa STATISTICA versión 10 para Windows.

\section{Resultados}

Colonización micorrízica. El factor tiempo influyó de manera significativa sobre la colonización micorrízica (\%) en los tres ciclos analizados (tiempo: ciclo 1, 2, 3) $(F=144.3821 ; p<0.05)$; así mismo el efecto de la interacción de HMA y HSF influyó de manera significativa $(F=59.5884 ; p<0.05)$. En relación con la colonización, se encontraron los siguientes rangos: $6.6-22.8 \%$ en el primer ciclo, 52.3-89.1\% en el segundo y 64-85.7 \% en el tercero. La micorrización en el segundo y tercer ciclo fue mayor con respecto al primero, mostrando diferencias significativas (Tukey $<0.05$ ). Para los tres ciclos la micorrización fue significativamente mayor en las plantas inoculadas con el tratamiento HMA+HSF que en las inoculadas con el tratamiento de HMA (Tukey < 0.05) (Figura 1). El rango de colonización micorrízica en las plantas inoculadas con el tratamiento HMA osciló entre $6.6 \%$ (primer ciclo) a $64 \%$ (tercer ciclo) con el tratamiento HMA+HSF. La colonización micorrízica se detectó mediante la presencia de estructuras fúngicas tales como arbúsculos y vesículas (Figura 2).

Fósforo soluble en el suelo. El factor tiempo mostró un efecto significativo sobre el contenido de fósforo soluble en el suelo $(F=13.2947 ; \mathrm{p}<0.05)$; el efecto de la interacción de HMA y HSF no influyó de manera significativa $(F=0.7498 ; p=\mathrm{n} . \mathrm{s})$, pero sí influyeron significativamente el factor HMA $(F=115.9084 ; p<0.05)$ y el factor HSF

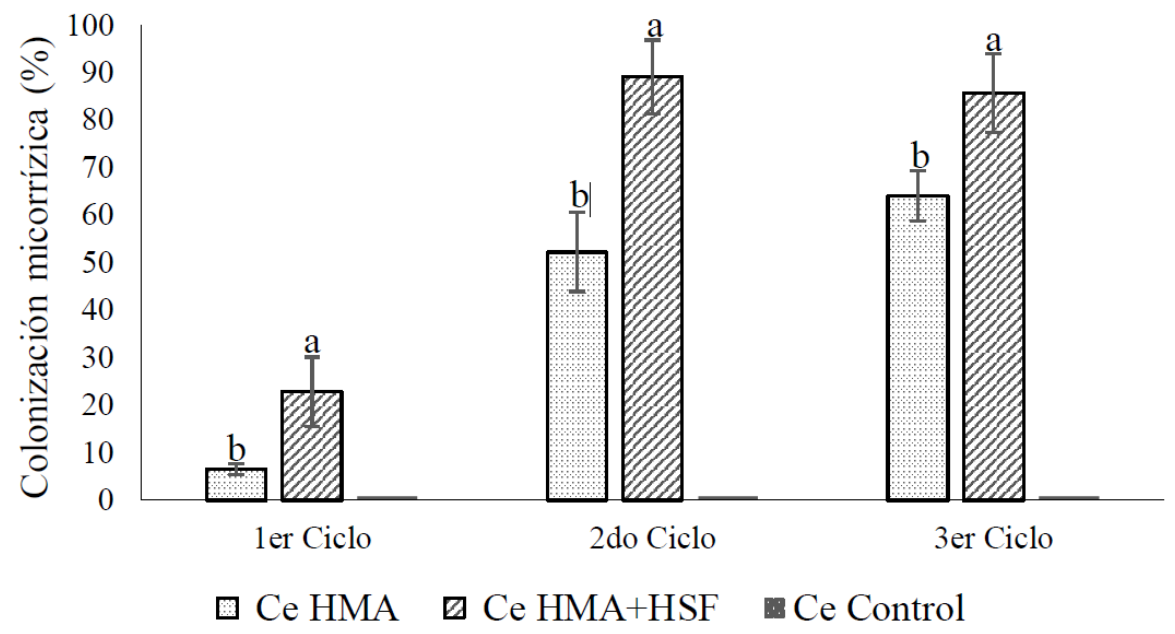

Figura 1. Colonización micorrízica (\%) de las plantas de Canavalia ensiformis (Ce) inoculadas con los hongos micorrízicos arbusculares (HMA), con hongos micorrízicos arbusculares y un hongo solubilizador de fósforo (HMA+HSF) y sin hongos (Control), en tres ciclos. Los datos corresponden al promedio de 3 repeticiones \pm desviación estándar. Letras idénticas entre las columnas indican que no existen diferencias significativas entre los tratamientos en cada ciclo (Tukey LSD, $p \leq 0.05$ ). 


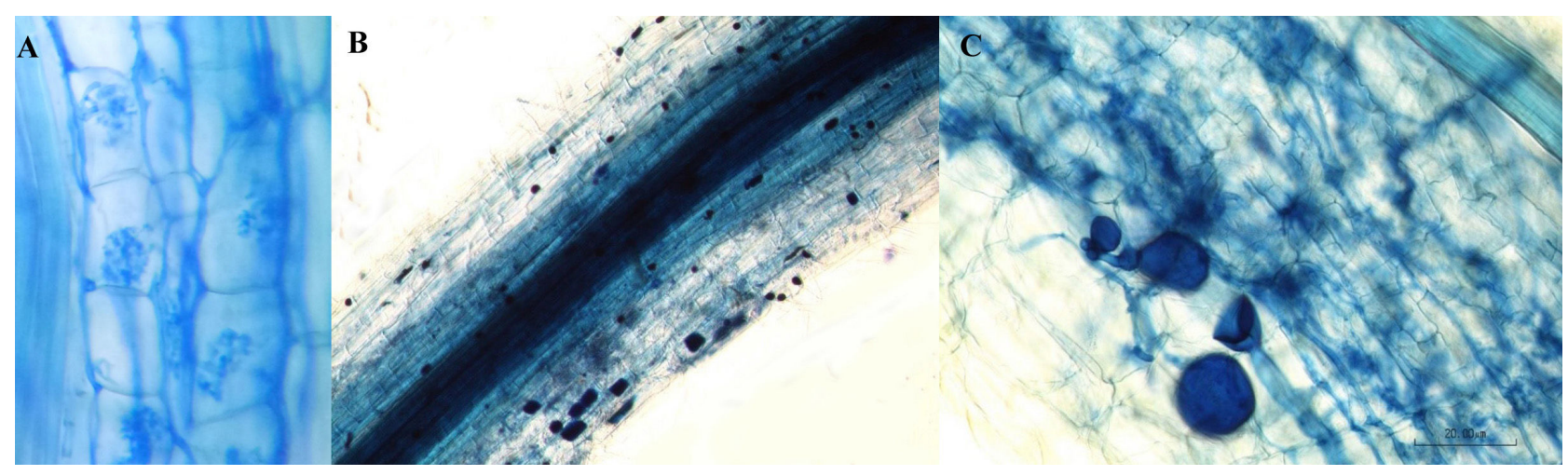

Figura 2. Estructuras fúngicas presentes en las raíces de C. ensiformis. A) arbúsculos, B y C) vesículas.

$(F=135.5201 ; p<0.05)$. En el primer ciclo, no se detectaron diferencias significativas en el contenido de fósforo entre las plantas inoculadas con los tratamientos HMA, HSF, HMA+HSF (Tukey = n.s), sin embargo, los valores fueron significativamente mayores que en las plantas con el tratamiento Control (Tukey < 0.05). En el segundo y tercer ciclo las plantas inoculadas con el tratamiento HMA+HSF presentaron un mayor contenido de fósforo disponible (Tukey $<0.05)$ que con el tratamiento HMA, HSF y Control. En ambos ciclos, las diferencias entre las plantas inoculadas con los tratamientos HMA y HSF no fueron significativas (Tukey = n.s), sin embargo, sí lo fueron con respecto al Control (Tukey < 0.05) (Figura 3).

Variables de crecimiento de las plantas. Altura de las plantas: La altura de las plantas varió de manera significativa ante el factor tiempo $(F=376.0556 ; p<0.05)$. Se detectó un efecto significativo de la interacción de HMA y HSF $(F=210.8651 ; p<0.05)$; así mismo del factor HMA $(F=112.3889 ; \quad p<0.05)$ y el factor HSF $(F=124.0079 ; p<0.05)$. En cada ciclo, se detectaron diferencias significativas entre las plantas inoculadas con los tratamientos HMA; HSF; HMA+HSF respecto al Control (Tukey $<0.05$ ). El rango de altura osciló entre $15.7 \mathrm{~cm}$ (Control/primer ciclo) a $64 \mathrm{~cm}$ (HSF/segundo ciclo). En el primer y tercer ciclo las plantas con la mayor altura fueron las inoculadas con los tratamientos HMA y HMA+HSF $\sin$ existir diferencias significativas entre ellas (Tukey $=n . s$ ), pero sí con las plantas inoculadas con los tratamientos HSF y Control (Tukey $<0.05$ ). En el segundo ciclo, la altura de las plantas inoculadas con el tratamiento HSF fue significativamente mayor que las inoculadas con los tratamientos HMA, HMA+HSF y el Control (Tukey< $<.05)$ ( Figura 4).

Número de hojas.- Tanto el factor tiempo como la interacción de HMA y HSF influyeron de manera significativa sobre el número de hojas en los tres ciclos analizados (tiempo: ciclo 1, 2, 3) (tiempo: $F=26.8776$; $p<0.05$; interacción: $F=10.7959 ; p<0.05)$. Así mismo influyeron significativamente los factores HMA $(F=4.5918 ; p<0.05)$ y $\operatorname{HSF}(F=10.7959 ; p<0.05)$. El número de hojas varió desde 6 (Control/primer ciclo) hasta 14 (HSF/segundo ciclo). En el primer ciclo no se detectaron diferencias significativas entre los tratamientos (HMA; HSF; HMA+HSF; Control) $($ Tukey = n.s). En el segundo ciclo las plantas inoculadas con el tratamiento HSF mostraron mayor número de hojas que con el resto de los tratamientos (Tukey < 0.05). En el tercer ciclo, el número de hojas de las plantas inoculadas con los tratamientos HMA y HMA+HSF, fue significativamente mayor que con las inoculadas con los tratamientos HSF y Control (Tukey $<0.05$ ) (Figura 5).

Número de nódulos: No se detectó un efecto significativo entre la interacción de HMA y HSF $(F=0.6585 ; p=\mathrm{n} . \mathrm{s})$. Sin embargo, se detectó un efecto significativo del factor HMA $(F=19.5203 ; p<0.05)$ y del factor HSF $(F=139.5203 ; p<0.05)$. El rango del número de nódulos osciló entre 46 (HMA) y 76 (HSF). El número de nódulos fue significativamente mayor en las plantas inoculadas con los tratamientos HSF y $\mathrm{HMA}+\mathrm{HSF}$, respecto a las inoculadas con los tratamientos HMA y Control (Tukey $<0.05$ ) (igura 6).

\section{Discusión}

Existen pocos estudios sobre los beneficios que brinda la co-inoculación de HMA y HSF a las plantas (Velázquez et al. 2005, Zaidi \& Khan 2006, Souchie et al. 2006, Babu \& Reddy 2011, Rodrigues-Cabral et al. 2012, Castillo et al. 2013, Ramírez-Gil et al. 2013, Serna 2013, Saxena et al. 2015, Velázquez et al. 2017, Perea-Rojas et al. 2019). Específicamente para la planta cobertera C. ensiformis, no 


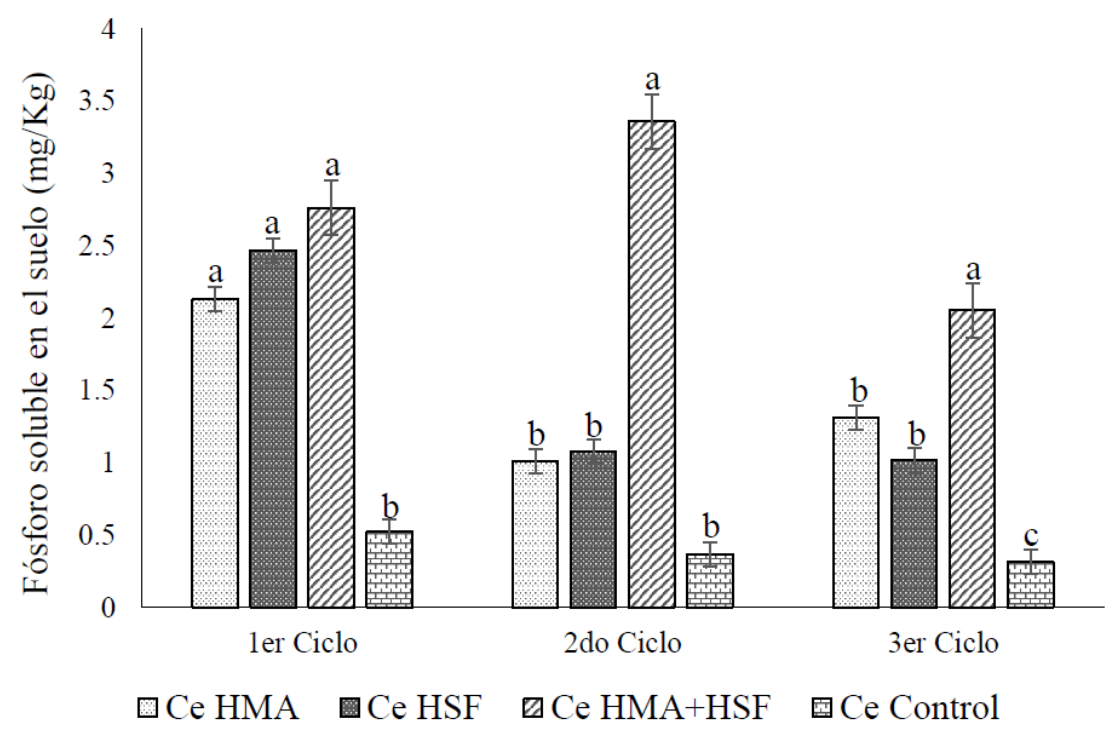

Figura 3. Fósforo soluble en el suelo $(\mathrm{mg} / \mathrm{Kg})$ de las plantas de Canavalia ensiformis (Ce) inoculadas con hongos micorrízicos arbusculares (HMA), con un hongo solublizador de fósforo (HSF), con hongos micorrízicos arbusculares y un hongo solubilizador de fósforo (HMA+HSF) y sin hongos (Control), en tres ciclos. Los datos corresponden al promedio de 3 repeticiones \pm error estándar. Letras idénticas entre las columnas indican que no existen diferencias significativas entre los tratamientos en cada ciclo (Tukey LSD, $p \leq 0.05$ ).

se encontraron trabajos relacionados con este tema de la coinoculación de HMA y HSF; de manera que este estudio representa el primer reporte a nivel mundial donde se evalúa el efecto de la interacción HMA y HSF sobre la colonización micorrízica, $\mathrm{P}$ soluble en el suelo, altura, número de hojas, número de nódulos en plantas de C. ensiformis.

De acuerdo a las categorías establecidas por Kormanik \& McGraw (1982), donde se definen 5 grados de colonización micorrízica: nula $(0 \%)$, baja (1-25\%), moderada (26$50 \%$ ), alta (51-75\%) y muy alta (76-100\%), de acuerdo a esta escala en este trabajo la colonización micorrízica fue de baja a moderada para el primer ciclo y alta a muy alta en el segundo y tercer ciclo. Por lo que se puede inferir que la especie $C$. ensiformis es altamente micotrófica.

En comparación con otros estudios en los que se evaluó la colonización micorrízica en plantas de $C$. ensiformis inoculadas exclusivamente con HMA; los valores aquí expuestos resultaron superiores a los informados por Martín et al. (2007), quienes detectaron un $84.61 \%$ de colonización micorrízica, Martín et al. (2009) 62.69$43.13 \%$, Martín-Alonso et al. (2012) 52.5-58.75 \%, MartínAlonso et al. (2013) 70 \%, García-Rubido et al. (2017) $58.45 \%$. En otros trabajos de inoculaciones de HMA en otras especies de plantas coberteras señalan rangos inferiores (Njeru et al. 2014 de 32.5-43.4 \%) a los resultados aquí expuestos. Sin embargo, Caldera et al. (2013) presentaron valores de colonización similares en la especie Vigna unguiculata (82-85.25\%).
Durante el tiempo de evaluación del ensayo la colonización micorrízica fue mayor en las plantas inoculadas con la interacción de los hongos micorrízicos y el hongo solubilizador (HMA+HSF). Por lo que se puede aseverar que la cepa de hongo solubilizador $P$. brevicompactum utilizada en este trabajo incrementó un $36.8 \%$ la colonización micorrízica en $C$. ensiformis, probablemente se estableció una interacción de sinergismo entre estos grupos de hongos que favoreció la micorrización. A la fecha existen pocos estudios de interacciones de HMA y HSF con efectos sinérgicos; Velázquez et al. (2017) en lechuga indicaron incrementos del $30 \%$ con inoculación Rhizophagus intraradices y Penicillium thomii. Velázquez et al. (2005), en plantas de tomate informaron incrementos del $13 \%$ al utilizar Glomus mosseae y Aspergillus niger. Resultados con efectos antagónicos fueron descritos en plantas de maíz y lechuga (McAllister et al. 1995), con efectos neutros en frijol caupí (Ramírez-Gil et al. 2013), en café (Perea-Rojas et al. 2019) y en jitomate (Arias et al. 2019). Cabe señalar que en estos últimos utilizaron el mismo consorcio de HMA y la cepa $P$. brevicompactum. La respuesta de las plantas a la inoculación depende de las compatibilidades funcionales en la fisiología y en la bioquímica de la interacción, entre los componentes microbianos; así arroja diferentes respuestas, dependiendo de la combinación de los microorganismos (Vázquez et al. 2000).

Los hongos micorrízicos arbusculares se caracterizan por la formación de arbúsculos y con excepción de los géneros 


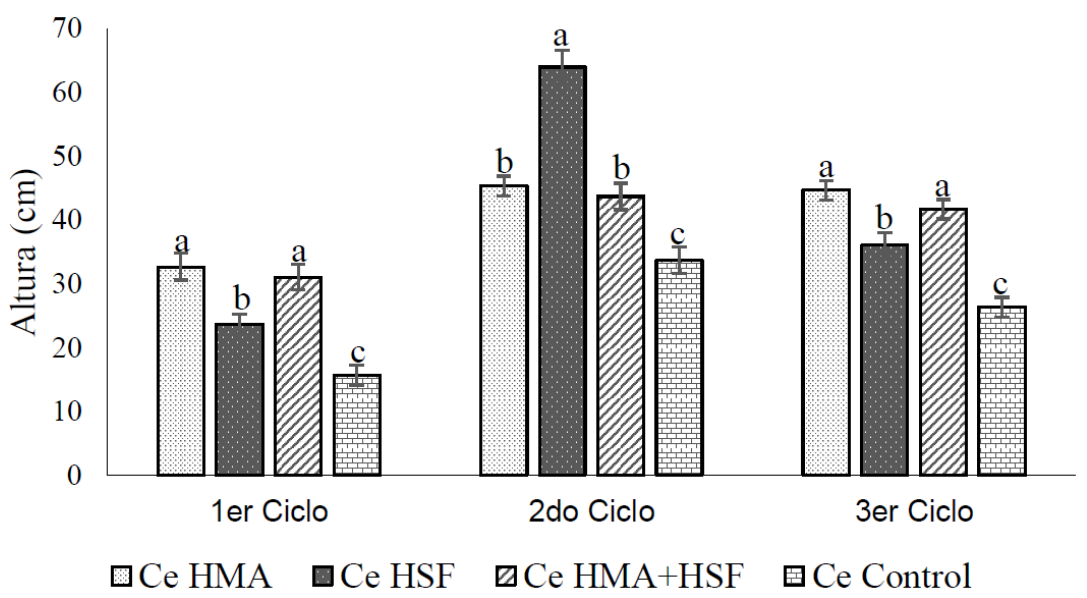

Figura 4. Altura (cm) de las plantas de Canavalia ensiformis (Ce) inoculadas con los hongos micorrízicos arbusculares (HMA), con un hongo solubilizador de fósforo (HSF), con hongos micorrízicos arbusculares y un hongo solubilizador de fósforo (HMA+HSF) y sin hongos (Control), en tres ciclos. Los datos son el promedio de tres repeticiones. Los datos corresponden al promedio de 3 repeticiones \pm desviación estándar. Letras idénticas entre las columnas indican que no existen diferencias significativas entre los tratamientos en cada ciclo (Tukey LSD, $p \leq 0.05$ ).

Gigaspora y Scutellospora la formación de vesículas (Peterson et al. 2004). En los resultados de este trabajo, sólo en el primer ciclo fue evidente la presencia de arbúsculos, mientras que en los tres ciclos se observaron vesículas. Esto corrobora lo planteado por Alarcón \& Ferrera-Cerrato (2000), quienes mencionaron que a pesar de que los arbúsculos son estructuras características de los HMA, estos no perduran en el tiempo y sólo se mantienen por unas 2 semanas. Después de este periodo, se observa la formación de un septo en la hifa del arbúsculo y la estructura se colapsa, luego son degradados completamente y las células de la planta regresan a su fisiología normal (Camarena-Gutiérrez 2012). En cuanto a las vesículas, según Aguilera-Gómez et al. (2007), algunos géneros de estos hongos las forman, están compuestas principalmente por lípidos, siempre están presentes intercelularmente en la corteza de la raíz y son reservorios de nutrimentos para el hongo.

Para el establecimiento de este experimento se utilizó suelo deficiente en $\mathrm{P}$ soluble $(0.28 \mathrm{mg} / \mathrm{Kg})$; después de cuatro meses de inoculadas la plantas con los hongos, el contenido de P fue de $3.35 \mathrm{mg} / \mathrm{Kg}$. Es decir, la interacción entre hongos micorrízicos y el solubilizador favoreció un incremento de $3.07 \mathrm{mg} / \mathrm{Kg}$ de $\mathrm{P}$ soluble en el suelo de las plantas. Por lo que los resultados son prometedores y la coinoculación de estos dos grupos de hongos puede ser una alternativa para aumentar la disponibilidad de este elemento, que generalmente se encuentra atrapado por iones metálicos de $\mathrm{Ca}, \mathrm{Al}$ y Fe.

Babu \& Reddy (2011), presentaron incrementos similares (3.1 $\mathrm{mg} / \mathrm{Kg}$ ) en plantas de bambú inoculadas con Aspergillus tubingensis y un consorcio de HMA. El incremento de $\mathrm{P}$ soluble en el suelo en este trabajo fue superior al obtenido por Perea-Rojas et al. (2019), en plantas de café $(2.93 \mathrm{mg} / \mathrm{Kg})$ con la inoculación del mismo consorcio de HMA y la misma cepa de P. brevicompactum, sin embargo, en ese estudio con la interacción de los HSF hubo un incremento de $4.9 \mathrm{mg} / \mathrm{Kg}$. De manera similar a la colonización micorrízica, en esta variable existe una respuesta diferencial de las especies de plantas ante las interacciones de los microorganismos (Vázquez et al. 2000).

El beneficio que ofrece el uso del HSF solo y en interacción con HMA fue notorio en los resultados obtenidos para las variables de crecimiento de las plantas de C. ensiformis (altura y número de hojas). Debido a que no existen antecedentes de co-inoculaciones de HMA y HSF en $C$. ensiformis, sólo se pueden comparar con estudios de co-inoculaciones en otras especies de leguminosas. Jagandi et al. (2017), en plantas de chícharo inoculadas con una bacteria solubilizadora de fósforo (Bacillus polymyxa) y un HMA (Rhizophagus fasciculatus) indicaron incrementos en la altura de $33.4 \mathrm{~cm}$. Ramírez-Gil et al. (2013), en plantas de frijol caupí inoculadas con un HSF (Mortierella sp.) y un HMA (Glomus fasciculatum) presentaron en sus resultados un aumento de $14 \mathrm{~cm}$ en la altura. En este trabajo se obtuvieron incrementos de altura de $29 \mathrm{~cm}$ en las plantas co-inoculadas con la interacción de HMA y HSF, además de $48.3 \mathrm{~cm}$ en las inoculadas con el hongo fosfatosolubilizador. Estos resultados son superiores a los de los estudios anteriormente referidos.

Existen estudios que evidencian que $C$. ensiformis tiene una alta capacidad para fijar nitrógeno atmosférico en asociación simbiótica con las bacterias de los géneros Rhizobium y Bradyrhizobium (Quiroga-Madrigal et al. 2006). En este trabajo realizado a nivel de invernadero, la 


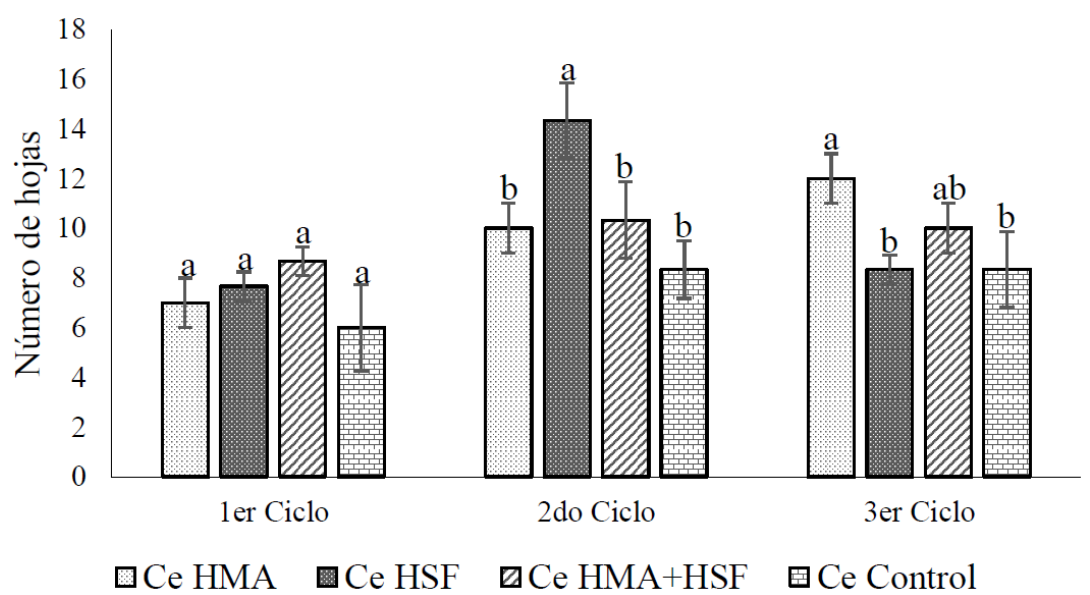

Figura 5. Número de hojas de las plantas de Canavalia ensiformis (Ce) inoculadas con los hongos micorrízicos arbusculares (HMA), con un hongo solubilizador de fósforo (HSF), con hongos micorrízicos arbusculares y un hongo solubilizador de fósforo (HMA+HSF) y sin hongos (Control), en tres ciclos. Los datos corresponden al promedio de 3 repeticiones \pm desviación estándar. Letras idénticas entre las columnas indican que no existen diferencias significativas entre los tratamientos en cada ciclo (Tukey LSD, $p \leq 0.05$ ).

formación de nódulos se vio favorecida por la presencia de HSF (76/planta) y de la interacción de HMA y HSF (69/planta). Pommeresche \& Hansen (2017), plantean que independientemente de la especie de leguminosa, si se encuentran aproximadamente 15 nódulos las bacterias fijadoras de nitrógeno están funcionando bien, si la cantidad de nódulos excede 100 por planta la nodulación es satisfactoria. Por lo que se puede inferir que en este estudio la nodulación tuvo un nivel satisfactorio; es probable que el alto contenido de $\mathrm{P}$ solubilizado por el hongo solubilizador favoreció la formación de nódulos. Pommeresche \& Hansen (2017), afirman que los factores que obstaculizan la fotosíntesis en plantas, como el estrés hídrico y la falta de otros nutrientes, también reducirá la fijación biológica de nitrógeno.
En el suelo los microorganismos (bacterias, hongos y otros) establecen interacciones, lo que es esencial para garantizar los ciclos de los nutrientes y los procesos de descomposición de la materia orgánica en cualquier ecosistema terrestre debido a los procesos biológicos como la oxidación, la reducción y la mineralización (Vandenkoornhuyse et al. 2015). Tales interacciones han demostrado su contribución al crecimiento de las plantas y a la calidad de los suelos; por lo tanto, constituyen aspectos críticos que deberán ser considerados en el desarrollo de una agricultura sostenible y buen funcionamiento del ecosistema (Pedraza et al. 2010).

El uso de coberteras como C. ensiformis inoculada con HMA y un HSF, dado que es una especie altamente micotrófica y con un alto grado de especificidad con las

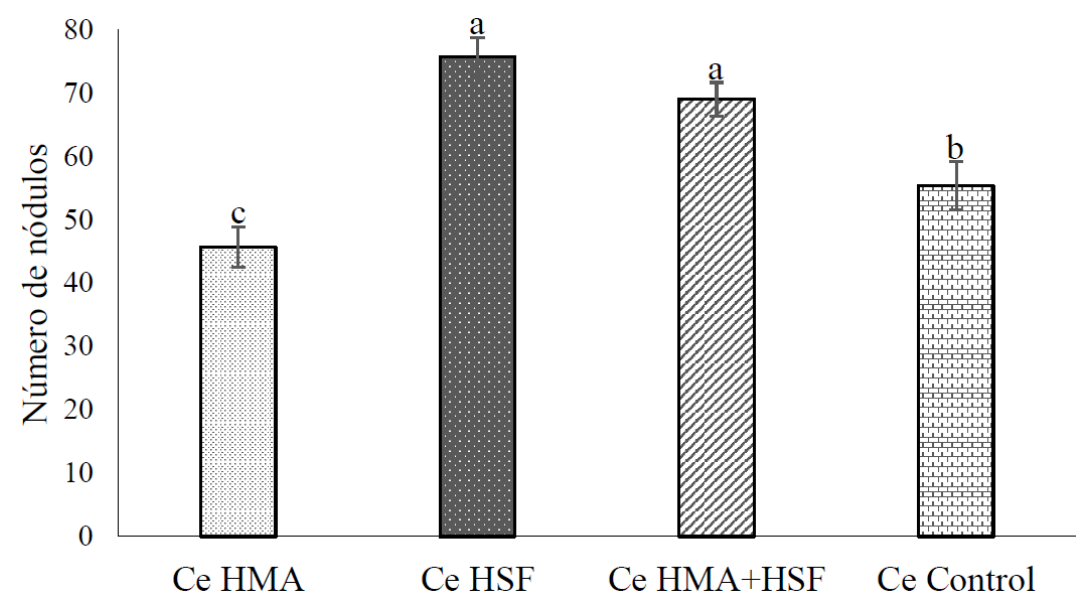

Figura 6. Número de nódulos de las plantas de Canavalia ensiformis (Ce) inoculadas con los hongos micorrízicos arbusculares (HMA), con un hongo solublizador de fósforo (HSF), con hongos micorrízicos arbusculares y un hongo solubilizador de fósforo (HMA+HSF) y sin hongos (Control), en tres ciclos. Los datos corresponden al promedio de 3 repeticiones \pm la desviación estándar. Letras idénticas entre las columnas indican que no existen diferencias significativas entre los tratamientos en cada ciclo (Tukey LSD, $p \leq 0.05$ ). 
bacterias fijadoras de nitrógeno simbióticas tiene gran potencial para ser utilizada en agricultura actual, pues conlleva al mejoramiento de los suelos en cuanto al contenido nutricional aportando nitrógeno al suelo $\mathrm{y}$ cultivos acompañantes a través de la liberación directa de nitrógeno amoniacal, la senescencia de los nódulos y la descomposición de la planta al finalizar su clico de vida (Dubach \& Ruselle, 1994). Se recomienda continuar estudiando el efecto de la interacción de estos grupos de hongos en esta especie y en otras leguminosas, que sean utilizadas como abonos verdes.

\section{Agradecimientos}

La primera autora agradece a CONACyT por la beca proporcionada para realizar la maestría en Ciencias Agropecuarias en la Facultad de Ciencias Agrícolas de la Universidad Veracruzana. A Dora Trejo Aguilar del laboratorio de Organismos Benéficos de la Facultad de Ciencias Agrícolas de la Universidad Veracruzana por proporcionar el inóculo micorrícico Rizofermic y prestar el invernadero, a Wendy Sangabriel Conde por su asesoría, a Yajaira Baeza, Alejandro Quirino y Sandra Lizveth Enríquez por su apoyo en el procesamiento de las muestras de esta investigación.

\section{Literatura citada}

Aguilera-Gómez LI, Olalde-Portugal V, Arriaga MR, Contreras-Alonso R. 2007. Micorrizas arbusculares. Ciencia Ergo Sum 14: 300-306.

Alarcón A, Ferrera-Cerrato R. 2000. Ecología, fisiología y biotecnología de la micorriza arbuscular. México, DF: Mundi-Prensa: Colegio de Postgraduados. ISBN 10: 968746223X; ISBN 13: 9789687462233

Arias RM, Romero AJ, Bañuelos J, De La Cruz Y. 2019. Inoculación de hongos solubilizadores de fósforo y micorrizas arbusculares en plantas de jitomate. Revista Mexicana de Ciencias Agrícolas 10: 1747-1755. DOI: https://doi.org/10.29312/remexca.v10i8.1558

Babu A, Reddy M. 2011. Dual inoculation of arbuscular mycorrhizal and phosphate solubilizing fungi contributes in sustainable maintenance of plant health in fly ash ponds. Water Air \& Soil Pollution 219: 3-10. DOI: https://doi.org/10.1007/s11270-010-0679-3

Beyra-Matos A, Reyes-Artiles G, Hernández-Valdés L, Herrera-Oliver P. 2004. Revisión Taxonómica del género Canavalia DC. (Leguminosae-Papilionoideae) en Cuba. Revista Academia Colombiana de Ciencias Exactas 28: 157-175

Bray RH, Kurtz LT. 1945. Determination of Total Organic and Available Forms of Phosphorus in Soils. Soil Science
59: 39-45. DOI: http://dx.doi.org/10.1097/00010694194501000-00006

Caldera E, Acosta K, Garcés G, Petit B, Gutiérrez W, Pérez C. 2013. Respuesta del cultivo fríjol (Vigna unguiculata L. Walp) variedad Catatumbo a la inoculación con micorrizas nativas y comerciales bajo condiciones controladas. Redieluz 3: 157-164.

Camarena-Gutiérrez G. 2012. Interacción planta-hongos micorrízicos arbusculares. Revista Chapingo Serie Ciencias Forestales y del Ambiente 18: 409-421. DOI: https://doi.org/10.5154/r.rchscfa.2011.11.093

Cano MA. 2011. Interacción de microorganismos benéficos en plantas: Micorrizas, Trichoderma spp. y Pseudomonas spp. Una revisión. UDCA Actualidad y Divulgación Cientifica 14: 15-31.

Castillo C, Morales A, Rubio R, Barea JM, Borie F. 2013. Interactions between native arbuscular mycorrhizal fungi and phosphate solubilizing fungi and their effect to improve plant development and fruit production by Capsicum annuum L. African Journal of Microbiology Research 7: 3331-3340. DOI: https://doi.org/10.5897/ AJMR2012.2363

Dubach M, Russelle MP. 1994. Forage legume roots and nodules and their role in nitrogen transfer. Agronomy Journal 86: 259-266. DOI: https://doi.org/10.2134/ agronj1994.00021962008600020010x

Edwards AC, Walker RL, Maskell P, Watson CA, Rees RM, Stockdale EA, Knox OG. 2010. Improving Bioavailability of Phosphate Rock for Organic Farming. In: Lichtfouse E, ed. Genetic Engineering, Biofertilisation, Soil Quality and Organic Farming. Francia: Sustainable Agriculture Reviews. pp. 99-117. ISBN: 978-90-481-8740-9

García M, Álvarez M, Treto E. 2002. Estudio comparativo de diferentes especies de abonos verdes y su influencia en el cultivo del maíz. Cultivos Tropicales 23: 19-30.

García-Rubido M, Rivera-Espinosa R, Cruz-Hernandez Y, Acosta-Aguiar Y, Cabrera JR. 2017. Respuesta de Canavalia ensiformis (L.) a la inoculación con diferentes cepas de hongo micorrízico arbuscular en un suelo Farl. Cultivos Tropicales 3: 7-12.

Giovannetti M, Mosse B. 1980. An evaluation of Ttechniques for measuring vesicular arbuscular mycorrhizal infection in roots. New Phytologist 84: 489-500. DOI: http://dx.doi.org/10.1111/j.1469-8137. 1980.tb04556.x

Gryndler M, Vosátka M, Hrŝelová H, Catská V, Chvátalová I, Jansa J. 2002. Effect of dual inoculation with arbuscular mycorrhizal fungi and bacteria on growth and mineral nutrition of strawberry. Journal of Plant Nutrition 25: 1341-1358. DOI: https://doi.org/10.1081/ $\underline{\text { PLN-120004393 }}$ 
Jangandi S, Negalur CB, Narayan, Lakshman HC. 2017. Synergistic effect between phosphate solubilizing bacteria and vesicular-arbuscular mycorrhizal fungi on growth and p uptake in Cajanus cajana L. (Pigeon pea). International Journal of Bioassays 6.01: 5211-5213. DOI: http://dx.doi.org/10.21746/ijbio.2017.01.005

Kormanik PP, McGraw AC. 1982. Quantification of vesicular-arbuscular mycorrhizae in plant roots. In: Schenck NC, ed. Methods and Principles of Mycorrhizal Research. Minnesota: American Phytopathological Society. pp. 37-45. ISBN-10: 0890540462; ISBN-13: 978-0890540466

Li HY, Yang GD, Shu HR, Yang YT, Ye BX, Nishida I, Zheng CC. 2006. Colonization by the arbuscular mycorrhizal fungus Glomus versiforme induces a defense response against the root-knot nematode Meloidogyne incognita in the grapevine (Vitis amurensis Rupr.), which includes transcriptional activation of the class III chitinase gene VCH3. Plant Cell Physiology 47: 154-163. DOI: https://doi.org/10.1093/pcp/pci231

Martín GM, Costa-Rouws JR, Urquiaga S, Rivera RA. 2007. Rotación del abono verde Canavalia ensiformis con maíz y micorrizas arbusculares en un suelo nitisol ródico éutrico de Cuba. Agronomía Tropical 57: 313-321.

Martín GM, Rivera R, Arias L, Rentería M. 2009. Efecto de la Canavalia ensiformis y micorrizas arbusculares en el cultivo del maíz. Revista Cubana de Ciencia Agrícola 43: 191-199.

Martín-Alonso GM, Rivera-Espinosa R, Arias-Pérez L, Pérez-Díaz A. 2012. Respuesta de la Canavalia ensiformis A la inoculación micorrízica con Glomus cubense (CEPA INCAM-4), su efecto de permanencia en el cultivo del maíz. Cultivos Tropicales 33: 20-28.

Martín-Alonso GM, Rivera-Espinosa R, Pérez-Díaz A. 2013. Efecto de canavalia, inoculación micorrízica y dosis de fertilizante nitrogenado en el cultivo del maíz. Cultivos Tropicales 34: 60-67.

McAllister CB, García-Romera I, Martín J, Godeas A, Ocampo JA. 1995. Interaction between Aspergillus niger van Tiegh. and Glomus mosseae. (Nicol. \& Gerd.) Gerd. \& Trappe. New Phytologist 129: 309-316. DOI: https:// doi.org/10.1111/j.1469-8137.1995.tb04301.x

Miransari M, Bahrami HA, Rejali F, Malakouti MJ. 2008. Using arbuscular mycorrhiza to alleviate the stress of soil compaction on wheat (Triticum aestivum L.) growth. Soil biology and biochemistry 40: 1197-1206. DOI: https:// doi.org/10.1016/j.soilbio.2007.12.014

Njeru E, Avio L, Sbrana C, Turrini A, Bocci G, Bàrberi P, Giovannetti M. 2014. First evidence for a major cover crop effect on arbuscular mycorrhizal fungi and organic maize growth. Agronomy Sustainable Development 34:
841-848. DOI: https://doi.org/10.1007/s13593-013-0197y

Oberson A, Frossard E, Bühlmann C, Mayer J, Mäder P, Lüscher A. 2013. Nitrogen fixation and transfer in grassclover leys under organic and conventional cropping systems. Plant and Soil 371: 237-255. DOI: https:// doi.org/10.1007/s11104-013-1666-4

Pedraza RO, Teixeira KRS, Fernández-Scavino A, Garcíade Salamone I, Baca BE, Azcón R, Baldani VLD, Bonilla R. 2010. Microorganismos que mejoran el crecimiento de las plantas y la calidad de los suelos. Revisión. Ciencia y Tecnología Agorpecuaria 11: 155-164. DOI: https://doi.org/10.21930/rcta.vol11 num 2 art:206

Perea-Rojas YC. 2013. Estudio preliminar del potencial solubilizador de fosfato tricálcico por micromicetos saprobios de suelos del Estado de Veracruz. BsC. Thesis. Universidad Veracruzana, México.

Perea-Rojas YC, Arias RM, Medel-Ortíz R, Trejo-Aguilar D, Heredia G, Rodríguez-Yon Y. 2019. Effects of native arbuscular mycorrhizal and phosphate-solubilizing fungi on coffee plants. Agroforestry Systems 93: 961-972. DOI: https://doi.org/10.1007/s10457-018-0190-1

Peters M, Franco LO, Schmidt A, Hincapié B. 2003. Especies forrajeras multipropósito opciones para productores del Trópico Americano. Cali: Centro Internacional de Agricultura Tropical (CIAT).

Peterson RL, Massicote HB, Melville LH. 2004. Mycorrhizas: Anatomy and cell Biology.Ottawa: NRC Research Press. ISBN-13: 978-0851999012

Phillips JM, Hayman DS. 1970. Improved Procedures for Clearing Roots and Staining Parasitic VesicularArbuscular Mycorrhizal Fungi for Rapid Assessment of Infection. Transactions of the British Mycological Society 55: 158-161. DOI: http://dx.doi.org/10.1016/ S0007-1536(70)80110-3

Pommeresche R, Hansen S. 2017. Examen de la actividad de los nódulos en raíces de leguminosas. Noruega: FertilCrop Documento técnico.

Quiroga-Madrigal RR, Ponce-Díaz P, Pinto-Ruíz R, Bran RAA, Velasco-Zebadúa ME, Zuart-Macías JL, CamasGómez R, Soto-Pinto ML, León-Martínez NS. 2006. La asociación de cultivos maíz-canavalia: ventajas agroecológicas y económicas. México: Fundación PRODUCE Chiapas. ISBN 970-9825-02-X

Ramírez-Gil JG, Osorno-Bedoya L, Osorio-Vega NW, Morales-Osorio JG. 2013. Alternativas Microbiológicas para Mejorar el Crecimiento del Caupí. Revista Facultad Nacional de Agronomía Medellín 66: 7035-7044.

Restrepo-Correa SP, Pineda-Meneses EC, Ríos-Osorio LA. 2017. Mecanismos de acción de hongos y bacterias empleados como biofertilizantes en suelos agrícolas: una 
revisión sistemática. Ciencia Tecnología Agropecuaria 18: 335-351. DOI: http://dx.doi.org/10.21930/rcta.vol18 _num2_art:635

Reyes-Jaramillo I. 2011. La micorriza arbuscular (MA) centro de la rizósfera: comunidad dinámica del suelo. Contactos 81: 17-23.

Rodrigues-Cabral JS, Cristina-de Assis K, Guimarães-Silva F, Luiz-Souchie E, Carbone-Carneiro MA. 2012. Plántulas de anacardo del cerrado brasileño inoculadas con hongos micorrízicos arbusculares y microorganismos solubilizadores de fosfato. Agrociencia 46: 809-821.

Saxena J, Saini A, Ravi I, Chandra S, Garg V. 2015. Consortium of Phosphate-solubilizing Bacteria and Fungi for Promotion of Growth and Yield of. Chickpea (Cicer arietinum). Journal of Crop Improvement 29: 353-369. DOI: https://doi.org/10.1080/15427528.2015. $\underline{1027979}$

Serna GLS. 2013. Efecto de la inoculación conjunta con hongos micorrizales y microorganismos solubilizadores de fósforo en plantas de aguacate. $\mathrm{PhD}$. Thesis. Universidad Nacional de Colombia.

Souchie EL, Saggin-Júnior OJ, Silva EMR, Campello EFC, Azcón R, Barea JM. 2006. Communities of Psolubilizing bacteria, fungi and arbuscular mycorrhizal fungi in grass pasture and secondary forest of Paraty, RJBrazil. Anais Academia Brasileira de Ciências 78: 1-11. DOI: http://dx.doi.org/10.1590/S0001-3765200600010 $\underline{0016}$

Souchie EL, Azcón R, Barea JM, Silva EMR, SagginJúnior OJ. 2010. Enhancement of clover growth by inoculation of P-solubilizing fungi and arbuscular

Editor de sección: Pablo Cuevas Reyes

Contribución de los autores: LPR , RMAM diseñaron el estudio, realizaron las inoculaciones, medición de variables, análisis estadísticos, interpretación de los resultados y escribieron el artículo. RMO y YCE contribuyeron a la interpretación de los resultados, la revisión y aprobación del manuscrito final. mycorrhizal fungi. Anais da Academia Brasileira de Ciências 82: 771-777. DOI: https://doi.org/10.1590/ $\underline{\mathrm{s} 0001-37652010000300023}$

Vandenkoornhuyse P, Quaiser A, Duhamel M, Le Van A, Dufresne A. 2015. The importance of the microbiome of the plant holobiont. New Phytologist 206: 1196-206. DOI: https://doi.org/10.1111/nph.13312

Vázquez MM, César S, Azcón R, Barea JM. 2000. Interactions between arbuscular mycorrhizal fungi and other microbial inoculants (Azospirillum, Pseudomonas, Trichoderma) and their effects on microbial population and enzyme activities in the rhizosphere of maize plants. Applied Soil Ecology 15: 261-272. DOI: https://doi.org/ 10.1016/S0929-1393(00)00075-5

Velázquez MS, Elíades L, Irrazabal G, Saparrat M, Cabello M. 2005. Micobización con Glomus mosseae y Aspergillus niger en plantas de Lycopersicon esculentum. Journal of Agricultural Technology 1: 315-326.

Velázquez MS, Cabello MN, Elíades LA, Russo ML, Allegrucci N, Schalamuk S. 2017. Combinación de hongos movilizadores y solubilizadores de fósforo con rocas fosfóricas y materiales volcánicos para la promoción del crecimiento de plantas de lechuga (Lactuca sativa L.). Revista Argentina de Microbiología 49: 347-355. DOI: http://dx.doi.org/10.1016/j.ram.2016. $\underline{07.005}$

Zaidi A, Khan MS. 2006. Co-inoculation effects of phosphate solubilizing microorganisms and Glomus fasciculatum on green gram-Bradyrhizobium. Turkish Journal of Agriculture and Forestry 30: 223-230. 